\title{
Atmospheric Scale Interaction on Wintertime Intermountain West Low-Level Inversions
}

\author{
ROBERT R. GILLIES \\ Utah Climate Center, and Department of Plants, Soils, and Climate, Utah State University, Logan, Utah \\ SHIH-YU WANG AND MARTY R. BOOTH \\ Utah Climate Center, Utah State University, Logan, Utah
}

(Manuscript received 5 November 2009, in final form 24 February 2010)

\begin{abstract}
Persistent winter inversions result in poor air quality in the Intermountain West of the United States. Although the onset of an inversion is relatively easy to predict, the duration and the subsequent breakup of a persistent inversion event remains a forecasting challenge. For this reason and for this region, historic soundings were analyzed for Salt Lake City, Utah, with reanalysis and station data to investigate how persistent inversion events are modulated by synoptic and intraseasonal variabilities. The results point to a close linkage between persistent inversions and the dominant intraseasonal (30 day) mode that characterizes the winter circulation regime over the Pacific Northwest. Meteorological variables and pollution (e.g., particulate matter of $\leq 2.5$ - $\mu \mathrm{m}$ diameter, PM2.5) revealed coherent variations with this intraseasonal mode. The intraseasonal mode also modulates the characteristics of the synoptic (6 day) variability and further influences the duration of persistent inversions in the Intermountain West. The interaction between modes suggests that a complete forecast of persistent inversions is more involved and technically beyond numerical weather prediction models intended for the medium range ( $\sim 10$ day). Therefore, to predict persistent inversions, the results point to the adoption of standard medium-range forecasts with a longerterm climate diagnostic approach.
\end{abstract}

\section{Introduction}

It is well known that winter inversions often result in poor air quality in certain regions of the Intermountain West. Here, distinct topographic conditions tend to maintain the pooling of stable, relatively cold air in valleys and mountain basins, resulting in persistent inversions (Lockhart 1943; Wolyn and McKee 1989; Whiteman et al. 1999, 2001; Billings et al. 2006). These inversions subsequently trap air pollutants and degrade the air quality over time (Holzworth 1962,1967). Although the occurrence of inversions is relatively easy to forecast, an accurate prediction of their duration and dissipation, as well as their relation with air quality, remains less resolved (e.g., Reeves and Stensrud 2009). Salt Lake City, Utah, is one of many cities in the Intermountain West that experiences prolonged, poor air quality during the

\footnotetext{
Corresponding author address: Dr. Robert R. Gillies, Utah Climate Center, Utah State University, 4825 Old Main Hill, Logan, UT 84322-4825.

E-mail: robert.gillies@usu.edu
}

winter months [December-February; Wolyn and McKee (1989)]. In 2007, in order to forecast winter inversion conditions along with expected air quality, the National Weather Service (NWS) at Salt Lake City began periodic special weather briefings for various state agencies before the onset of and during inversion situations (information online at http://www.wrh.noaa.gov/slc/projects/ AQ_Briefing/AQ_Briefing.htm). In these briefings, it was regularly mentioned that estimating inversion duration and pollution intensity was frequently difficult to specify in definitive terms.

Diurnal thermal and radiative forcing coupled with the progression of synoptic waves can enhance the chance for stagnant stable layers that might lead to persistent inversions (e.g., Whiteman 2000). Valley cold pools, for instance, often develop following a lower-level cold surge and midlevel warming associated with the approach of an upper-level ridge. The inversions then "wash out" with the passage of a synoptic trough after the cold surge (Wolyn and McKee 1989; Whiteman et al. 1999, 2001; Zhong et al. 2001; Reeves and Stensrud 2009). The sequence of such inversion developments coupled with the 
synoptic evolution also regulates air quality (Holzworth 1962).

The progression of synoptic waves is characterized by periodic features. There is the typical synoptic variability in the 2-8-day spectrum (Blackmon 1976) and lowerfrequency variability of planetary circulations at time scales ranging from 10 to 45 days (Horel and Mechoso 1988; Renwick and Wallace 1996; Lau and Nath 1999). The synoptic variability is due to the release of available potential energy driven by baroclinic conversion (e.g., Wallace et al. 1988). On the other hand, the lowerfrequency variability commonly referred to as intraseasonal variability (ISV) is attributed partly to free external Rossby waves that slowly propagate westward in response to the dominant $\beta$ effect (Branstator 1987; Lau and Nath 1999). Moreover, it has been found that the midlatitude ISV is connected to the tropical ISV [i.e., the Madden-Julian oscillation (MJO); Madden and Julian 2005]. The midlatitude response to the tropical ISV usually results in stationary or eastward-moving planetary waves (Mo and Paegle 2005).

In the Intermountain West, deep stable-layer development and the resulting poor air quality are usually associated with the presence of large-scale ridge systems over the West Coast (Wolyn and McKee 1989). As illustrated in Fig. 1a by the climatological 300-hPa geopotential height, the mean wintertime ridge dominating over the Pacific Northwest is the primary circulation feature linked to the so-called high season of persistent inversions. To inspect if this ridge undergoes the previously mentioned synoptic variability and the ISV, a power spectra analysis on the daily geopotential height $(Z)$ and meridional wind $(v)$ at $300 \mathrm{hPa}$ was performed. Sampled at the maximum center of the eddy geopotential height (white box in Fig. 1a) and the root-mean square of $v$ (dashed contour in Fig. 1a), the power spectra of $Z$ (Fig. 1b) and $v$ (Fig. 1c) reveal two dominant modes: a 2-8-day mode and a 20-40-day mode that are consistent with the documented time scales of the synoptic variability and the ISV, respectively.

Components of Fig. 1 therefore suggest a working hypothesis: that the occurrence of inversions and the subsequent air quality conditions in the Intermountain West are modulated by both the synoptic variability and the ISV. In light of the difficulties encountered in forecasting the duration of persistent inversions, we decided to investigate the linkage, as discussed previously, between the occurrence of inversions and the predominant atmospheric circulation variabilities, based upon observations in Salt Lake City. This paper presents the findings from a climate diagnostic approach applied to gain insights into the characteristics of persistent inversions in the Intermountain West. The data and our
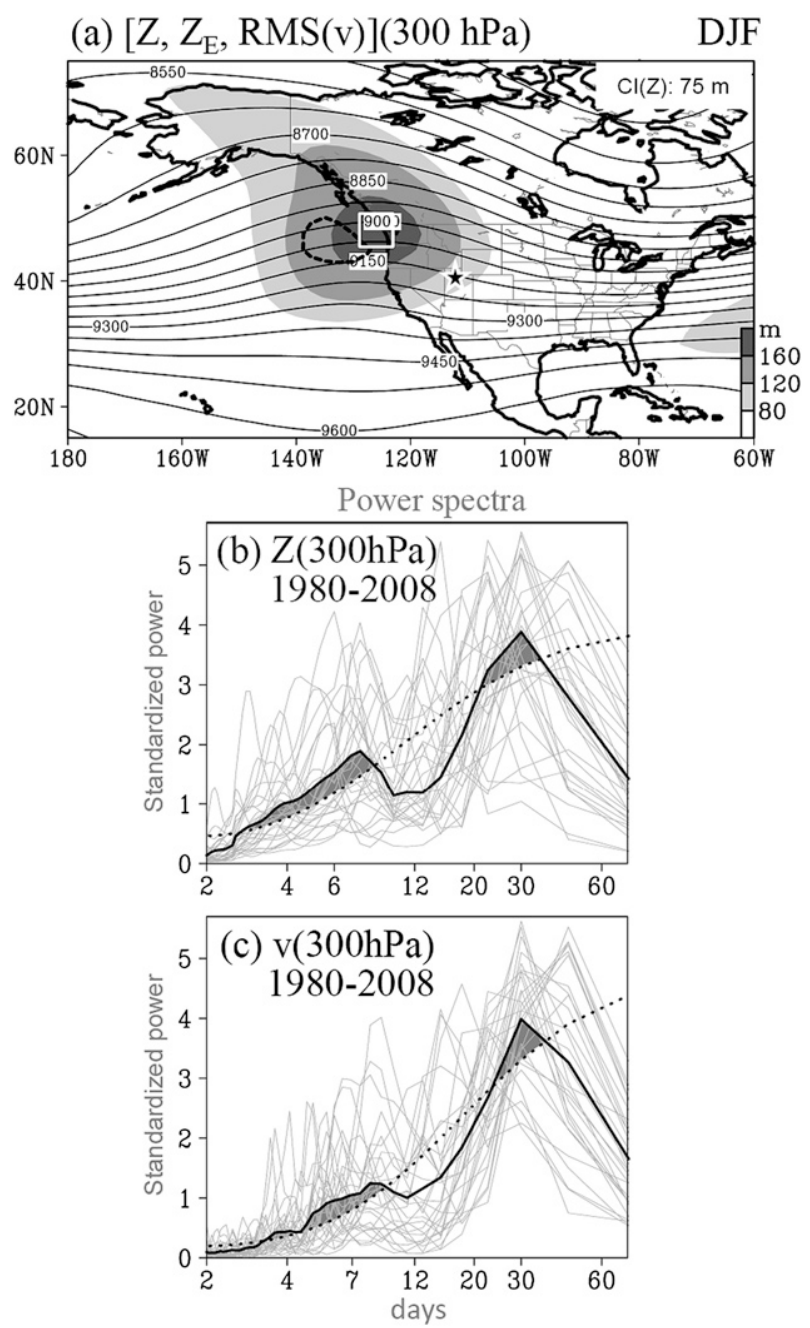

FIG. 1. (a) Mean 300-hPa geopotential height ( $Z$; contour interval $75 \mathrm{~m}$ ) during December-February superimposed with the eddy geopotential height ( $Z_{E}$; shadings) and the root-mean square of the daily $v$ wind [RMS $(v)$, dashed contour of $\left.17.5 \mathrm{~m} \mathrm{~s}^{-1}\right]$. Salt Lake City is marked by a star. Power spectra of daily (b) $Z$ $(300 \mathrm{hPa})$ and (c) $v(300 \mathrm{hPa})$ over the maximum centers of $Z_{\mathrm{E}}$ and $\operatorname{RMS}(v)$. Light curves represent the spectrum of individual years from 1980 to 2008, while thick solid curves depict their long-term average. Spectra above the $99 \%$ confidence level (dotted curves) are shaded.

methodology are introduced in section 2. Results and discussion are presented in section 3. Circulation features associated with the ISV and the synoptic variability are given in section 4. A summary with some conclusions is given in section 5 .

\section{Data and inversion definition}

\section{a. Datasets}

Upper-air soundings at the Salt Lake City International Airport (KSLC; elevation 1289 m) were utilized 


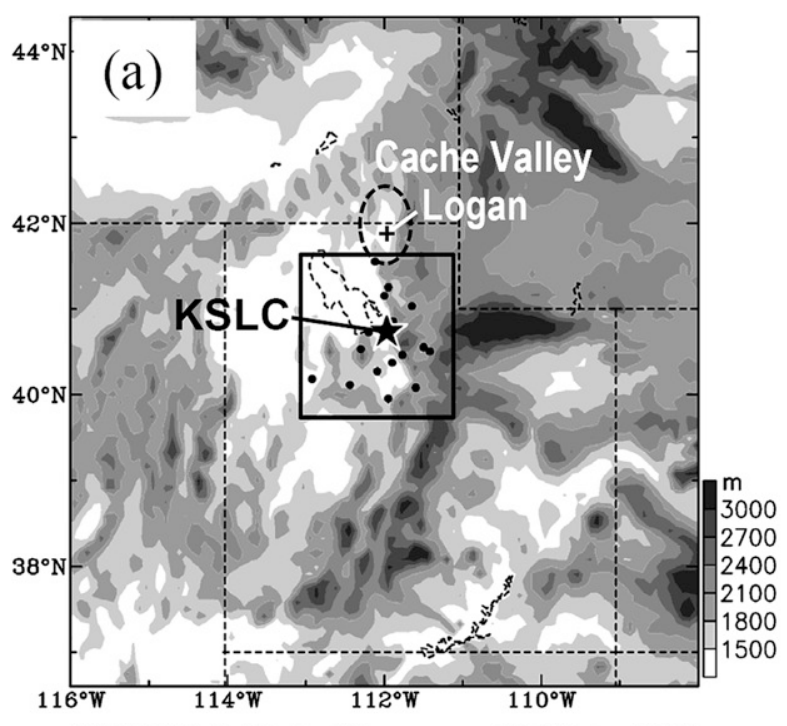

72572 SLC Salt Lake City
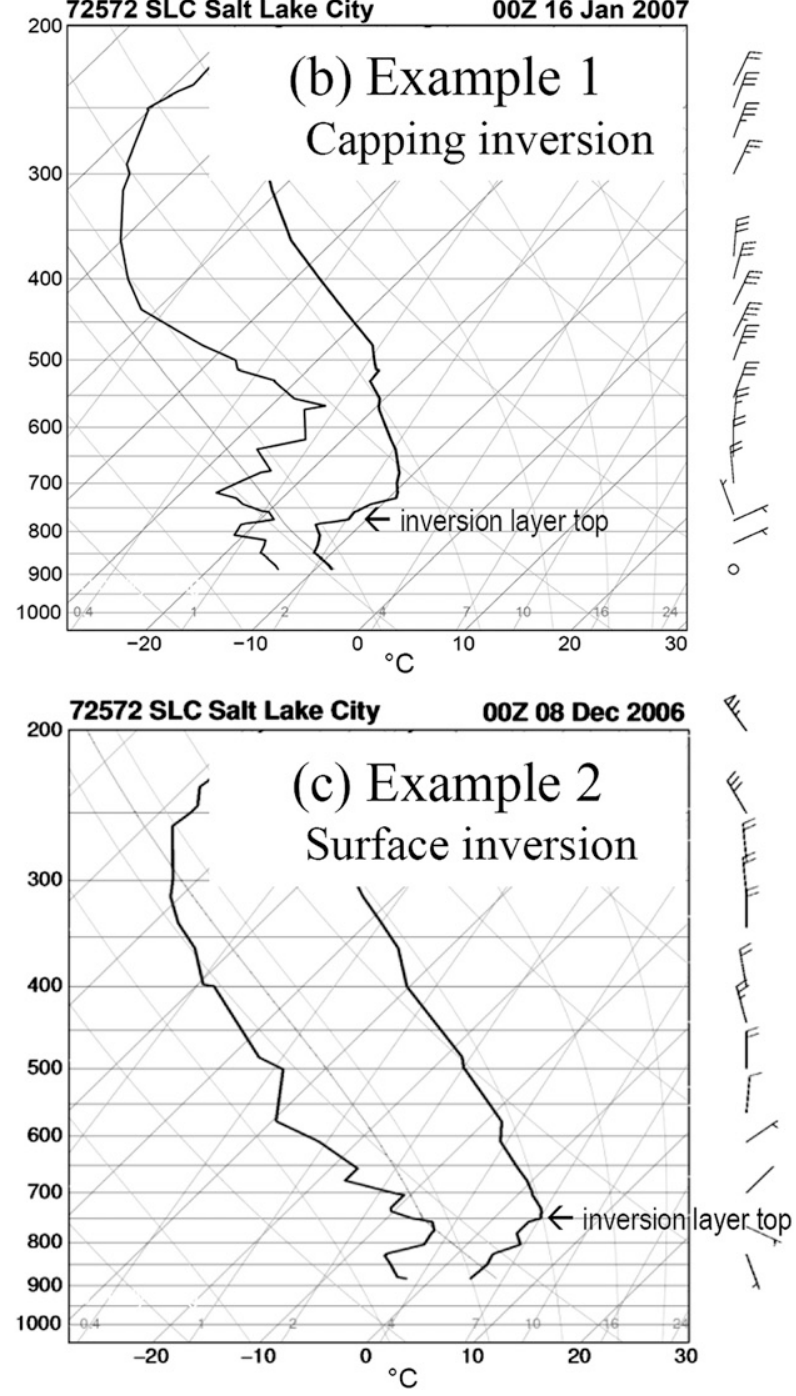

to characterize and analyze inversions over the period from December 1979 to February 2008. These soundings were obtained from the University of Wyoming (information online at http://weather.uwyo.edu/upperair/ sounding.html). As shown in Fig. 2a, KSLC is located in the Salt Lake Valley, embedded within the Great Basin. Surface observations from the NWS Cooperative Observer Program (COOP) stations were also utilized in the ensuing analysis, including temperature, precipitation, and snow depth. A total of 18 COOP stations within a $200 \mathrm{~km} \times 200 \mathrm{~km}$ domain surrounding KSLC below the elevation of $2000 \mathrm{~m}$ (Fig. 2a) were analyzed as being representative of the general surface conditions in the vicinity of KSLC; these are active COOP stations with over $95 \%$ data availability. Historical records and quality reports of the COOP station data are archived at the Utah Climate Center (online at http://climate.usurf.usu. edu/products/data.php).

Particulate matter (PM), also known as particle pollution, is a standard measurement of air pollution. PM is a complex mixture of extremely small dust, soot, and other particles measured in units of mass per cubic meter. PM of $2.5 \mu \mathrm{m}$ in diameter or smaller (PM2.5) is the most harmful to human lung tissue. Measurements of PM2.5 are continually conducted by the Environmental Protection Agency (EPA) at various locations in the Salt Lake Valley. For this study, we chose an air quality station in Salt Lake City (Utah Division of Air Quality site ID 49-035-3006) located approximately $6 \mathrm{mi}$ southeast of KSLC at the elevation of $1306 \mathrm{~m}$. The rationale behind this choice was that this particular station had the most complete set of daily measurements of PM2.5 for the longest period of time (1999-present). In addition, to evaluate how valley size may affect PM2.5, we included a comparative air quality station at Logan (site ID 49-005-0004; elevation $1380 \mathrm{~m}$ ), which is located in the relatively narrow Cache Valley; this is also depicted in Fig. 2a. PM2.5 data were obtained from the EPA Web site (http://www.epa.gov/ttn/airs/airsaqs/detaildata/ downloadaqsdata.htm). As a side note, the Logan site recorded PM2.5 once every 3 days beginning March 2000 and subsequently changed its recording frequency to once a day in May 2002.

For three-dimensional meteorological variables, we utilized two reanalysis datasets: the National Centers for

FIG. 2. (a) Topography and the locations of KSLC (star), nearby COOP stations (dots), the Cache Valley (dashed oval), and Logan (cross), and two examples of the 0000 UTC KSLC sounding of (b) a capping inversion on 16 Jan 2007 and (c) a surface inversion on 8 Dec 2006. Inversion layer tops are indicated. 
Environmental Prediction-National Center for Atmospheric Research (NCEP-NCAR) global reanalysis (Kalnay et al. 1996) and the North American Regional Reanalysis (NARR; Mesinger et al. 2006). The NCEPNCAR reanalysis was used primarily to depict the circulations, while the NARR dataset provided variables that are not included in operational soundings (e.g., vertical velocity) at grid points close to KSLC. The NARR was also used for filling in any missing observations in the soundings. Both reanalysis datasets were obtained from the National Oceanic and Atmospheric Administration/Office of Oceanic and Atmospheric Research/Earth System Research Laboratory's (NOAA/ OAR/ESRL) Physical Science Division (information online at http://www.cdc.noaa.gov).

\section{b. Inversion definition}

During each winter season, Salt Lake City is subjected to two main types of inversion layers: 1) a so-called capping inversion with an inversion lid capping a mixed or unstable layer at some altitude above the surface and 2) a surface inversion with a neutral or increasing temperature profile extending from the surface up to a certain height. Example soundings of capping and surface inversions are illustrated, respectively, in Figs. $2 \mathrm{~b}$ and 2c. In their study, Wolyn and McKee (1989) termed these two types of inversion as capping stable and deep stable layers, respectively. Under fair weather conditions, the stable boundary layer during the nighttime can be strong enough to persist throughout the daytime and form a capping inversion (Stull 2006). However, the depths of both the stable and mixed layers also vary in close association with the weather patterns. Since our focus here is on the synoptic variability and its modulation of inversion conditions, rather than the diurnal boundary layer evolution, potential complications resulting from any diurnal forcing (e.g., nocturnal inversion formation) were avoided by confining our analysis to just late-afternoon soundings (0000 UTC; 1700 local time).

Two factors were used to define the capping and surface inversions: lapse rate and wind speed. Analyzing the soundings of KSLC along with the soundings of three other locations in the Intermountain West, Wolyn and McKee (1989) concluded that a threshold lapse rate of less than or equal to $2.5^{\circ} \mathrm{C} \mathrm{km}^{-1}$ was characteristic of deep stable layers. Using this lapse rate, the 0000 UTC soundings at mandatory and significant levels were systematically analyzed as follows:

1) capping inversion-the temperature sounding was characterized by a lapse rate $>2.5^{\circ} \mathrm{C} \mathrm{km}^{-1}$ extending from the ground to the bottom of a neutral or increasing temperature profile, and
2) surface inversion - the temperature sounding had a lapse rate $\leq 2.5^{\circ} \mathrm{C} \mathrm{km}^{-1}$ from the ground to the top of the level where the lapse rate transitions to $>2.5^{\circ} \mathrm{C} \mathrm{km}^{-1}$.

Occasionally, a very shallow stable layer forms close to the ground beneath a layer with a lapse rate exceeding $2.5^{\circ} \mathrm{C} \mathrm{km}^{-1}$ capped by another inversion layer. Such a phenomenon is usually due to widespread snow accumulation and/or very cold surface air temperatures and is formed by radiative cooling. When this shallow radiative cooling occurred and the resulting near-surface stable layer was shallower than $150 \mathrm{~m}$, we defined this specific type of case as a capping inversion instead of a surface inversion. We only examined soundings below $500 \mathrm{hPa}$ to exclude stratospheric or upper-level frontal inversions.

The top of an inversion was defined by the layer in which the lapse rate changes from being less than or equal to $2.5^{\circ} \mathrm{C} \mathrm{km}^{-1}$ to greater than that amount, and is accompanied by a wind direction change exceeding $60^{\circ}$ or a wind speed change of more than $10 \mathrm{~m} \mathrm{~s}^{-1}$. Considering changes in the wind field also serves to determine inversion layer tops when multiple inversions are present. For reference purposes, the inversion layer tops in examples 1 and 2 are indicated in Figs. 2 b and 2c, respectively. In example 2 , the first possible inversion layer top $(\sim 800 \mathrm{hPa})$ was dismissed, as it did not satisfy the wind direction criterion. Additionally, the average wind speed within the inversion layer must be less than $5 \mathrm{~m} \mathrm{~s}^{-1}$. This wind speed criterion follows that used in Reeves and Stensrud (2009). Taking into account wind speed in the inversion-layer analysis also helped exclude frontal inversions. The dates and classification of the identified inversion cases are shown in Fig. 3a.

After identifying and classifying inversion conditions, we defined a "total inversion event" in terms of the number of consecutive inversion days. A total inversion event could consist of either a mixture of capping and surface inversions or only a single type of inversion. For example, a 7-day total inversion event may comprise capping inversions for the first 3 days and surface inversions for the latter 4 days, such as the case occurring on 3-9 December 2006 (circled in Fig. 3a). A 1-day occurrence of either a capping or surface inversion was defined simply as a single event.

In the composite analysis that follows, the 0000 UTC temperature soundings were bilinearly interpolated onto uniform levels with a 10-hPa interval below $500 \mathrm{hPa}$ and a $25-\mathrm{hPa}$ interval above $500 \mathrm{hPa}$, using mandatory and significant levels. By specifying such intervals, weak and shallow nocturnal inversions were filtered out, leaving the predominance of strong and episodic inversions. Snapshots of time-height cross sections of the interpolated 

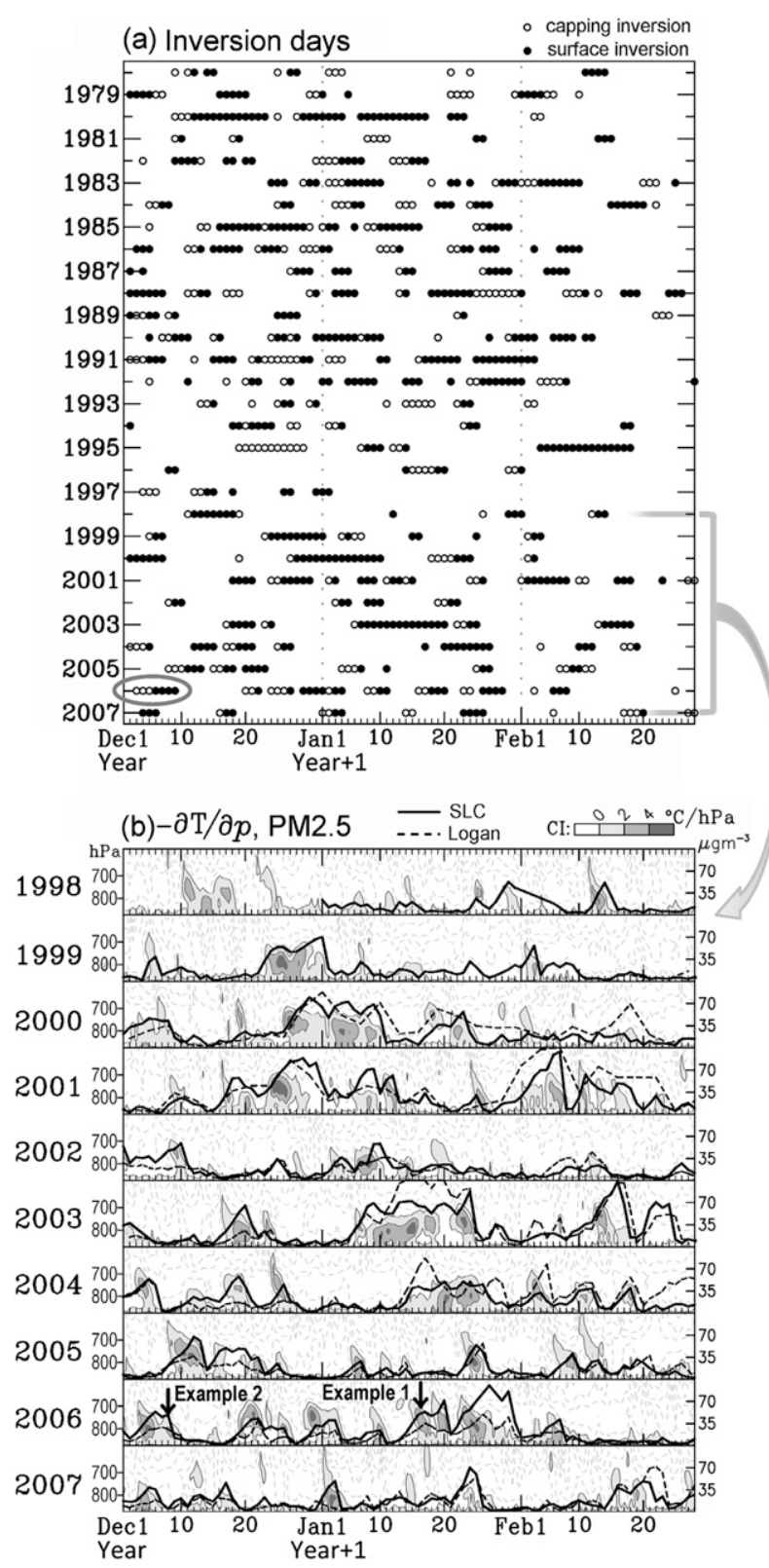

FIG. 3. (a) Calendar of surface inversions (dots) and capping inversions (circles) during the winters from December 1979 to February 2008. The gray circle indicates the example event of 3-9 Dec 2006. (b) Time-height cross sections of vertical temperature gradients at KSLC from 1999 to 2008 (shaded contours; interval $2^{\circ} \mathrm{C} \mathrm{hPa}^{-1}$ ) superimposed with the PM2.5 concentrations in Salt Lake City (solid line) and Logan (dashed line). Note that $\mathrm{PM} 2.5 \geq 35 \mu \mathrm{g} \mathrm{m}^{-3}$ is the EPA alert level for air quality. The two sounding examples as shown in Fig. 2 are indicated (2006).

vertical temperature gradients at KSLC from 1999 to 2008 are shown in Fig. 3b. It was found that inversion development (outlined by positive contours) tends to occur initially at higher altitudes and subsequently descend toward the surface. This feature has been noted in Wolyn and McKee (1989, their Fig. 7) and Reeves and Stensrud (2009) and will be discussed further in section $3 \mathrm{~b}$.

\section{Results}

As an initial analysis, Fig. 3b depicts the strong association between the development of persistent inversions and the PM2.5 concentrations in both Salt Lake City and Logan. Most of the moderate to dangerous air alert readings (i.e., PM2.5 $\geq 35 \mu \mathrm{g} \mathrm{m}^{-3}$ ) were found when inversions lasted for 4 days or longer. During such persistent inversions, the PM2.5 concentration usually builds slowly at the beginning of a total inversion event but dissipates relatively quickly at the end of the event. In addition, there is a marked coherence in the PM2.5 concentrations between the Salt Lake Valley and the Cache Valley, indicative of PM2.5 homogeneity under such persistent inversion conditions. There is also a tendency for the alert-level PM2.5 in Logan to last about a day longer than in Salt Lake City, suggesting that the existence of orographic modulation in smaller valleys may serve to trap air pollutants for a longer period of time.

\section{a. Inversion climatology}

The probability density functions of inversion layer tops (Fig. 4a) reveal a peak altitude at $790 \mathrm{hPa}$ for the tops of surface inversions and a widespread altitude ranging between 600 and $800 \mathrm{hPa}$ for the tops of capping inversions. Shown alongside the scatter diagram of inversion-layer tops versus the $300-\mathrm{hPa}$ geopotential height at KSLC is their linear fit line, indicating a tendency of increasing geopotential height with decreasing altitude of the top of the capping inversions. Despite a wide scatter for capping inversions, the correlation coefficient of the fit line is significant at the $95 \%$ level. On the other hand, the top of the surface inversions is generally independent of the $300-\mathrm{hPa}$ geopotential height. As shown in Fig. 4b, the PM2.5 concentrations measured in Salt Lake City and the inversion layer tops follow a second-order polynomial relationship. There is also a tendency for large PM2.5 concentrations to occur under conditions of surface inversions rather than capping inversions, especially for those above the dangerous alert levels of PM2.5 (i.e., $>70 \mu \mathrm{g} \mathrm{m}^{-3}$ ). A similar second-order polynomial relationship exists for Logan PM2.5 concentrations (dashed line), though individual measurements in Logan are not plotted.

The frequency of the total inversion events with respect to event duration is plotted in Fig. 5a. A bimodal distribution of the inversion frequency is clearly visible, including a primary peak at 2-3 days with a secondary peak occurring at 14 days. Given the close association of inversions with the synoptic weather patterns, the 
(a) Inversion layer tops vs. Z(300hPa)
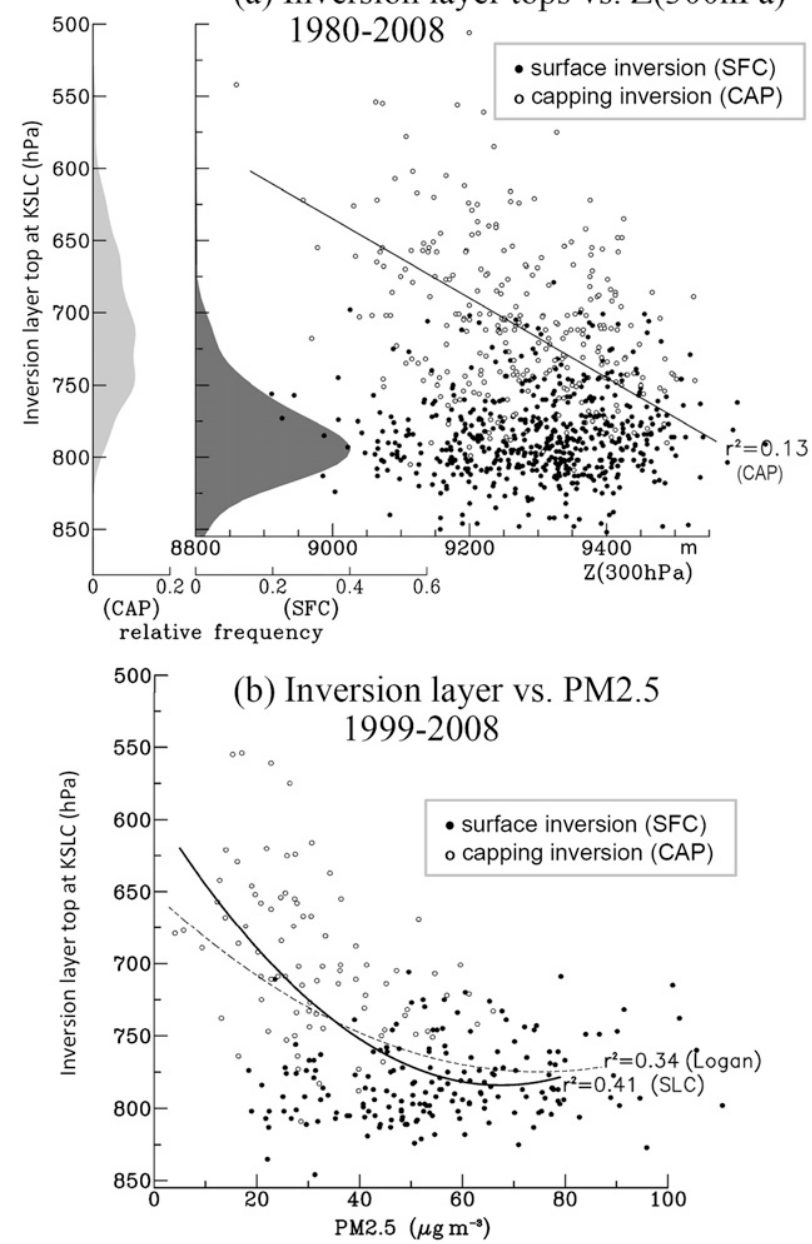

FIG. 4. (a) Scatter diagram of inversion layer tops ( $y$ axis) vs the 300-hPa geopotential height at KSLC ( $x$ axis) for all cases. Surface (capping) inversions are indicated by dots (circles), with a fit line for capping inversions. The probability density function of inversionlayer tops of the surface (capping) inversion is shown as dark- (light-) shaded curves to the left. (b) As in (a), but for inversion layer tops vs the PM2.5 concentrations ( $x$ axis). A second-order polynomial fit curve is added for Salt Lake City (solid line) and Logan (dashed line).

observed two frequency peaks of inversion duration imply two modes of weather cycles that (a) last for about a week ( $\sim 6$ days) and (b) a month ( $\sim 30$ days), consistent with the two dominant modes of the atmospheric circulation as depicted in the spectral analysis (cf. Figs. 1b and $1 \mathrm{c}$ ). From here onward throughout the text, we use the terms 6-day mode and 30-day mode for weather cycles $a$ and $b$.

Next, we analyzed the occurrence frequency of capping and surface inversion events with respect to their duration. For example, a consecutive 3 days of capping inversions would be categorized as a 3-day event, with those 3 days counted as the event frequency of capping
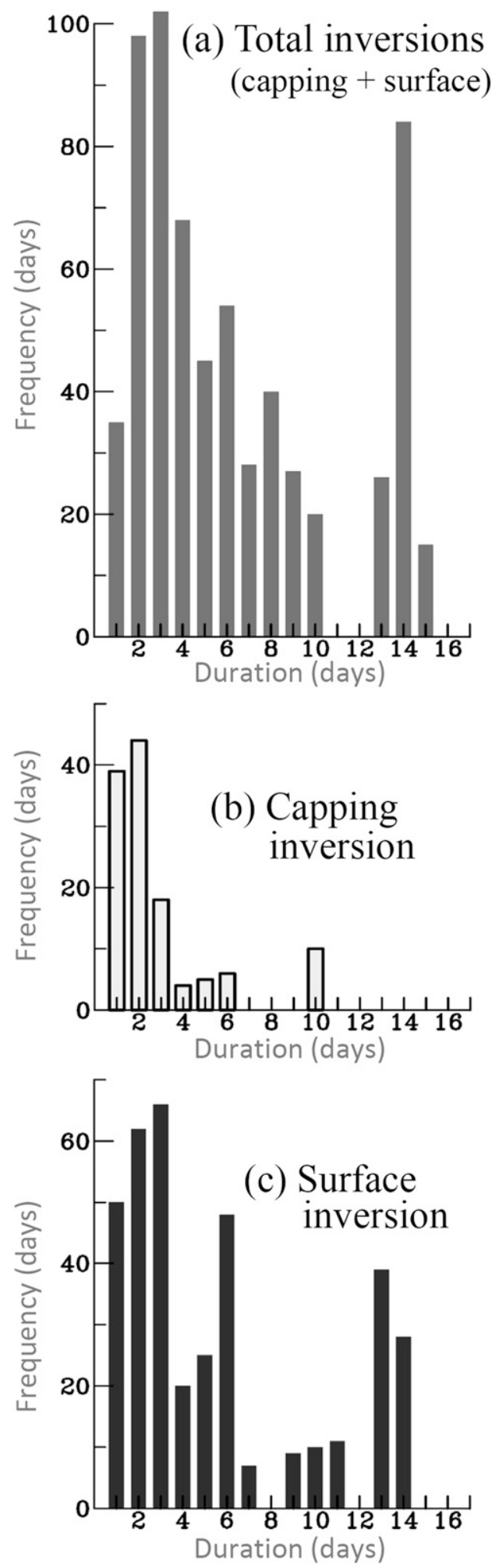

FIG. 5. Accumulated frequencies of (a) total inversion events, (b) capping inversions, and (c) surface inversions with respect to their duration in days. 
inversions. As shown in Figs. 5b and 5c, the duration of capping inversions is overall shorter ( $<4$ days) than that of surface inversions, while persistent inversion events ( $\geq 4$ days) mostly involve surface inversions. In other words, it is the surface inversion that is most likely associated with the 30-day mode.

\section{b. Composite analysis}

To depict the relationship between inversion developments and the aforementioned 6- and 30-day modes, we filtered the geopotential height of the KSLC soundings with 2-8 days for the 6-day mode (denoted as $\left.Z_{6 \mathrm{~d}}\right)$ and $20-40$ days for the 30-day mode (denoted as $Z_{30 \mathrm{~d}}$ ), using the second-order Butterworth bandpass filter. The filter was applied over the time period NovemberMarch. The procedure creates an index for the 6-day mode $\left(Z_{6 \mathrm{~d}}\right)$ and another index for the 30-day mode $\left(Z_{30 \mathrm{~d}}\right)$ based on the filtered geopotential height at $300 \mathrm{hPa}$.

Next, we applied an "index cycle" composite analysis introduced by Knutson and Weickmann (1987) and modified in Chen et al. (2009) with the $Z_{6 \mathrm{~d}}$ and $Z_{30 \mathrm{~d}}$ indices. If the amplitude of $Z_{30 \mathrm{~d}}$ on any day was greater than its standard deviation, the life cycle (with one trough and one ridge) encompassing this day was selected. If only one-half of the cycle occurred within the analysis period (i.e., the other half occurred in either November or March), this half cycle was used. In addition, if only one-half of the cycle reached the one standard deviation criterion but the other half of the cycle did not (there were four such cases during 1980-2008), then this half cycle was also used. For any given cycle of the $Z_{30 \mathrm{~d}}$ index, the cycle was evenly divided into eight phases, with phase 3 designated on the day of maximum amplitude and phase 7 as the day of minimum amplitude, as illustrated in Fig. 6a. Each phase covers a 3-day period centered on the second day. The same procedure was applied to the $Z_{6 \mathrm{~d}}$ index cycle (Fig. 6b) and divided into six phases (each representing 1 day), with phase 2 designated as the maximum amplitude and phase 5 as the minimum amplitude. These composite procedures were then applied to the 0000 UTC soundings and the NARR data, as well as daily observations of PM2.5 concentrations and surface variables. All of the composite fields were unfiltered.

The eight composite phases of the 30-day mode in terms of the vertical temperature gradient $(-\partial T / \partial p)$ for the KSLC sounding are shown in Fig. 7a. When comparing $-\partial T / \partial p$ with the composite anomalies of geopotential height and vertical velocity ${ }^{1}$ in Fig. $7 \mathrm{~b}$ (with

\footnotetext{
${ }^{1}$ The NARR vertical velocity was the domain average over KSLC, as outlined in Fig. 2a.
}
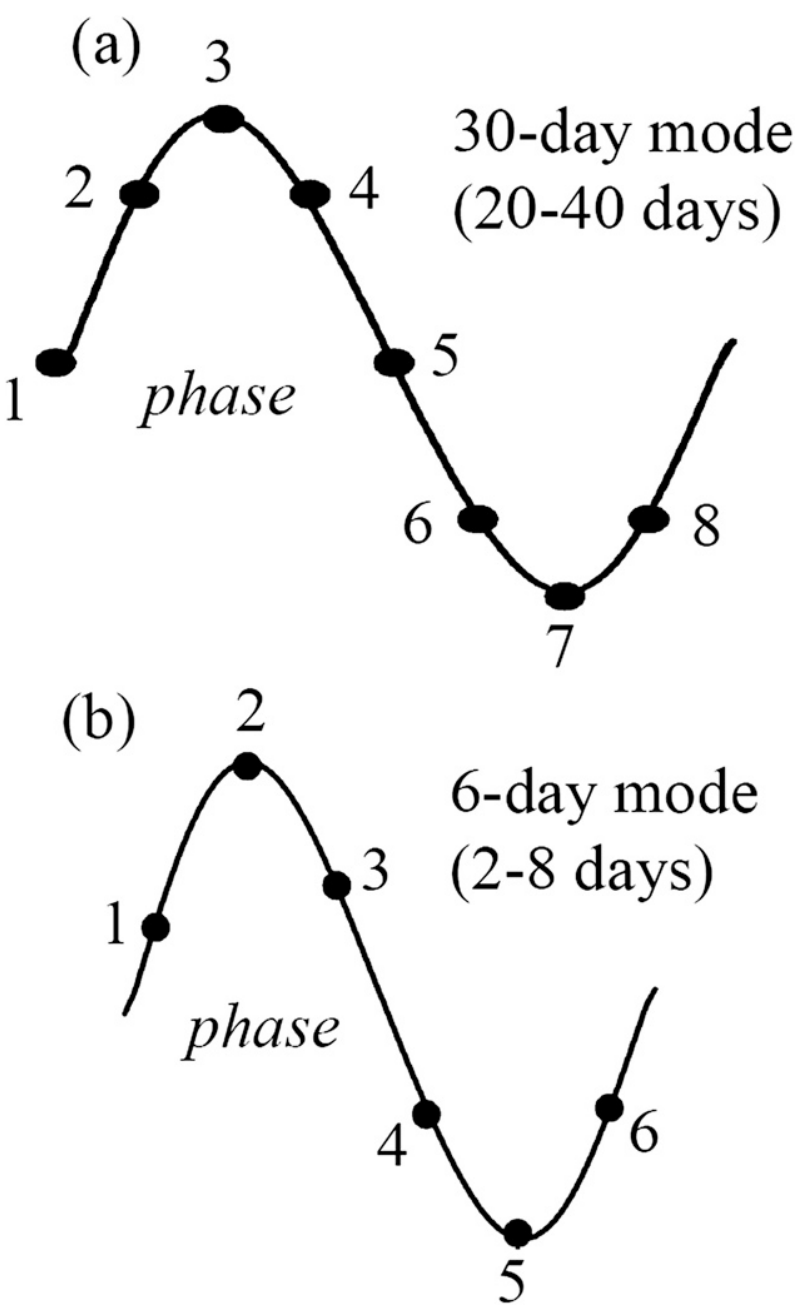

FIG. 6. Schematic illustrations of (a) the eight phases of the 30-day mode and (b) the six phases of the 6-day mode.

the climate mean removed), it is observed that the inversion layer forms at phases 7 and 8 near the $650-\mathrm{hPa}$ layer and is associated with the developing ridge and downward motion of the 30-day mode. The inversion layer then descends to $800 \mathrm{hPa}$ between phases 2 and 4 , when the 30-day mode ridge prevails over KSLC, and drastically dissipates at phase 5 as the trough progresses and ascending motion sets in. The altitude distribution of the inversion layer depicted in Fig. 7a is consistent with that shown in Fig. 4a; this also serves as validation of the inversion classification procedure outlined in section $2 b$.

Corresponding to the evolution of $-\partial T / \partial p$, the highest occurrence of capping inversions occurs around phases 8 and 1 (Fig. $7 \mathrm{c}$ ), when the ridge and descending motion are developing, and the peak frequency of the surface inversions appears later at phases 2 and 3, which is associated with deep, strong descent embedded in the core 
of the ridge. Sequential development of the surface inversion following the capping inversion also agrees with the case study by Wolyn and McKee (1989, their Fig. 7), except in our analysis both inversion types undergo a pronounced, cyclic evolution associated with the 30-day mode.

It is commonly known that inversions and bad air quality are usually cleared away during a frontal passage. In view of this, we examined the 0000 UTC NWS DiFAX surface maps ${ }^{2}$ and recorded the days when a cold front was within $150-\mathrm{km}$ radius of KSLC. From 2001 to 2008, the recorded days with a cold front passage near KSLC were accumulated with respect to the eight phases of the 30-day mode composite (not shown). The highest frontal frequency occurs at phase 6 (as illustrated by a cold front symbol in Fig. 7b) and is associated with the strongest ascending motion and the lowest static stability above the surface (cf. Fig. 7a). The peak frontal frequency at phase 6 also coincides with the lowest frequency of the capping and surface inversions combined.

At the surface, the PM2.5 concentration in Salt Lake City (Fig. 7c, thick solid line) reaches a maximum at phase 2 and remains high through phases 3 and 4, corresponding more with the surface inversion frequency rather than the capping inversion frequency. Such an association between PM2.5 and the surface inversions is in good agreement with that depicted in Fig. 4b. A drastic drop in PM2.5 occurs between phases 4 and 5 in response to the developing trough and upward motion and possibly to the increasing frontal frequency as well. The PM2.5 concentrations in Logan (dashed line) are generally consistent with those in Salt Lake City but are slightly higher. Moreover, the Logan PM2.5 variation appears to last a few days longer than the Salt Lake City PM2.5 variation during high-concentration days (cf. phase 3), suggesting that smaller valleys tend to more effectively trap cold air and build PM2.5 for a longer period of time. This feature reflects the known topographic modification of inversion properties and its impacts on air quality (Whiteman 2000).

The composite phases of surface daily maximum temperature, precipitation, and snow depth over the selected COOP stations are illustrated in Fig. 7d. The cyclic evolutions of these variables following the 30-day mode are readily visible. Compared to the PM2.5 concentrations, the daily maximum temperature remains relatively stable during phases $2-5$ and then drops at phase 6 .

\footnotetext{
${ }^{2}$ NWS DiFAX surface maps were provided by Colorado State University (information online at http://archive.atmos.colostate. $\mathrm{edu} /)$.
}

The temperature drop is accompanied by increased precipitation likely coupled with the increased frontal activity, as the ridge of the 30-day mode gives way to the approach of the trough. Snow depth subsequently increases at phase 6 , following the peak precipitation. The coherence between the synoptic system and the surface observations is not surprising; however, the close association between these surface observations and the 30-day mode clearly demonstrates the impacts of the ISV on winter weather in the Intermountain West.

Following the composite procedure, the six phases of the 6-day mode for the equivalent variables were constructed and are shown in Fig. 8. To take into account any possible impacts of the 30-day mode on the 6-day mode, the composite was further categorized into positive and negative phases of the $Z_{30 \mathrm{~d}}$ index. The composite evolutions of geopotential height and vertical velocity for the 6-day mode under positive $Z_{30 \mathrm{~d}}$ phases are very different (Fig. 8b) from those under negative $Z_{30 \mathrm{~d}}$ phases (Fig. 8f). For example, the trough system and associated ascending motion of the 6-day mode are substantially weaker under positive $Z_{30 \mathrm{~d}}$ phases, but are noticeably stronger under negative $Z_{30 \mathrm{~d}}$ phases. In the 6-day mode, vertical motion is coupled with the edges of the trough-ridge system (i.e., spatially in quadrature), which is typical in the quasigeostrophic dynamics of synoptic waves. In comparison, vertical velocity in the 30-day mode (Fig. 7b) is in phase with the trough-ridge system.

Embedded in the ridge and downward motion of the 30-day mode, inversion layers at phases 2 and 3 of the 6-day mode (Fig. 8a) are considerably stronger than those embedded in the trough and upward motion of the 30-day mode (Fig. 8e). This feature is particularly pronounced near the surface and is reflected by the fact that the surface inversion frequency is 3 times higher in the $Z_{30 \mathrm{~d}}$ ridge (Fig. 8c) than that in the $Z_{30 \mathrm{~d}}$ trough (Fig. 8g). In contrast, the frequency of the capping inversions is relatively unchanged in either case. Also noteworthy is that the frequency of the surface inversions undergoes a drastic drop at phase 4; this echoes the observation by Reeves and Stensrud (2009) that persistent valley cold pools are usually cleared by an approaching synoptic trough. The analysis of the frontal frequency in the 6-day mode composite (not shown) reveals the largest frontal activity at phase 4; thus, cold fronts associated with the approach of synoptic troughs may play a role in lifting the inversions (Fig. 8b). These results further exemplify the combined impacts of the 30- and the 6-day modes on the occurrence and type of inversion.

The PM2.5 concentrations also follow the 6-day mode evolution, with higher values during the ridge and lower values during the trough. The difference in the overall 


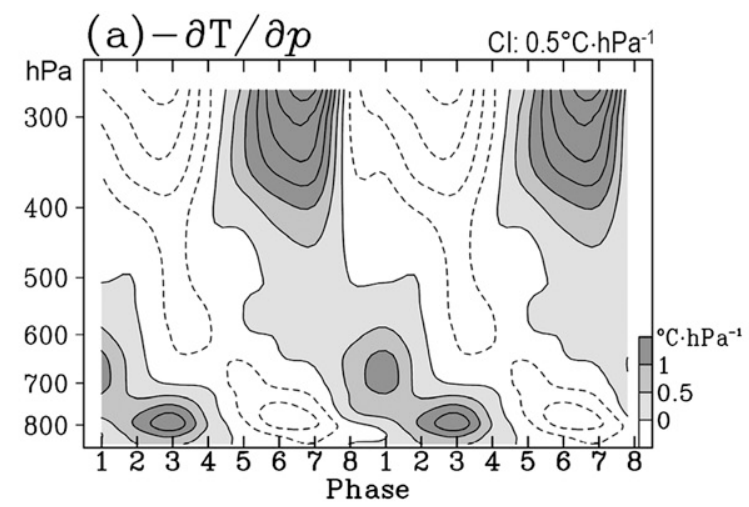

(b) $\Delta \mathrm{Z}, \Delta \omega$
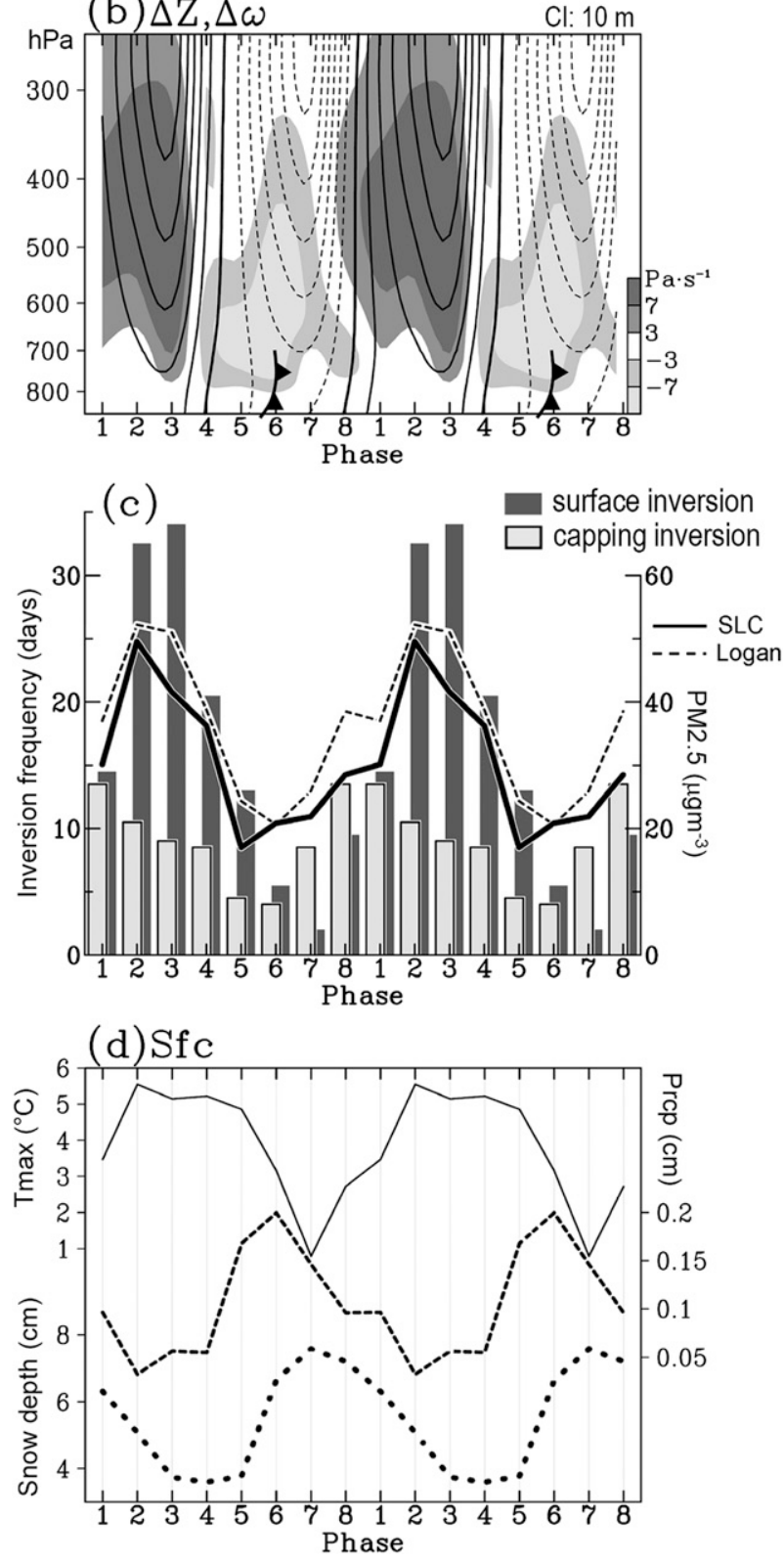

concentration between Figs. $8 \mathrm{c}$ and $8 \mathrm{~g}$ is obviously a result of the 30-day mode modulation. Compared to the 30-day mode composite, the PM2.5 concentrations in Logan are coherent with those in Salt Lake City, indicating a comparable influence of synoptic waves on air quality in different valleys. The variation amplitudes of the surface conditions associated with the 6-day mode are generally weaker under the $Z_{30 \mathrm{~d}}$ ridge (Fig. 8d) than those under the $Z_{30 \mathrm{~d}}$ trough (Fig. 8h), suggesting that the relatively quick passage of a synoptic trough is inadequate to clear off the alert-level PM2.5 concentrations. In addition, the precipitation variation associated with the 6-day mode is considerably enhanced under the $Z_{30 \mathrm{~d}}$ trough. This signifies a multiple-scale process from which the ISV influences precipitation by modulating the synoptic weather systems.

\section{Circulation patterns}

\section{a. ISV versus synoptic variability}

Applying the same filtering technique as for $Z_{6 \mathrm{~d}}$ and $Z_{30 \text { d }}$, the $300-\mathrm{hPa}$ geopotential height of the NCEPNCAR reanalyses during the analysis period was filtered and then correlated with the KSLC $Z_{6 \mathrm{~d}}$ and $Z_{30 \mathrm{~d}}$ indices at various time lags. These correlation results were then averaged throughout the 1980-2008 period, yielding a mean correlation map for each time lag and so depicting the structure and evolution of both modes.

As shown in Fig. 9a, the 6-day mode is characterized by a robust synoptic wave train propagating eastward (from day -3 to day +2 with a 1 -day interval). The wave train exhibits a steady pattern of eastward movement toward North America along $45^{\circ} \mathrm{N}$. Its structure and propagation resemble those depicted in Wallace et al. (1988, their Fig. 4). The 30-day mode (Fig. 9b) also depicts a wave train at a larger scale; however, its propagation is not as apparent as the 6-day mode despite a discernable pattern of eastward movement across North America. The weak propagation of the 30-day mode

FIG. 7. Composite of the eight phases of the 30-day mode for the (a) vertical gradient of temperature $(-\partial T / \partial p)$, (b) departures of the KSLC geopotential height (contours) and the NARR vertical velocity (shadings) from the climate mean, (c) frequencies of surface inversion (dark bars) and capping inversion (light bars) and the PM2.5 concentrations in Salt Lake City (thick curve) and Logan (dashed curve), and (d) daily maximum temperature (solid curve), precipitation (dashed curve), and snow depth (dotted curve) averaged from the COOP stations. The cold front symbol in (b) indicates the maximum frequency of frontal passages through Salt Lake City at phase 6. Contour intervals (CIs) are given atop (a) and (b). The eight phases are repeated for better illustration. 

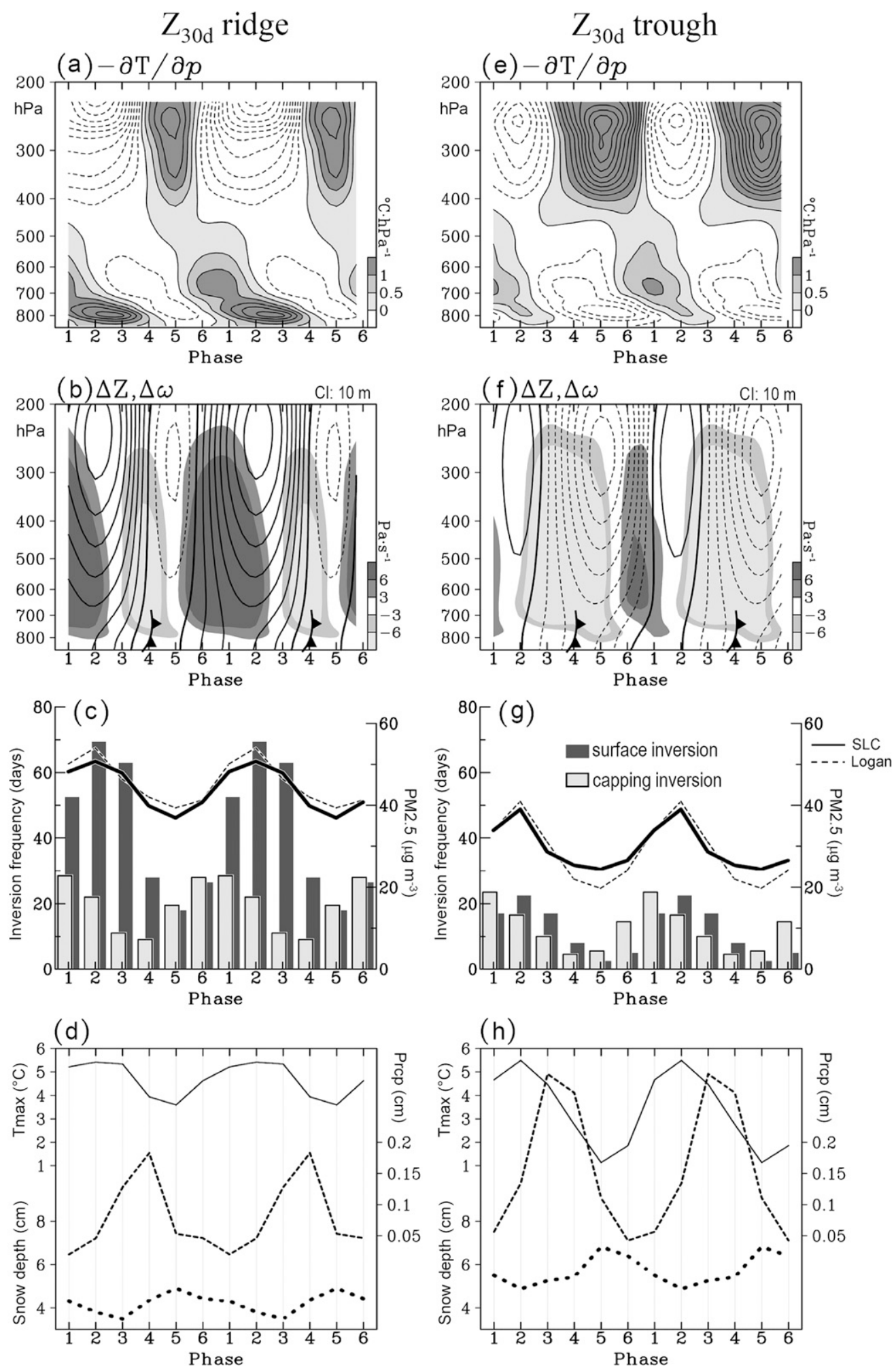

FIG. 8. As in Fig. 7, but for the six phases of the 6-day mode composite under (a)-(d) the 30-day-mode ridges and (e)-(h) the 30-day-mode troughs. 

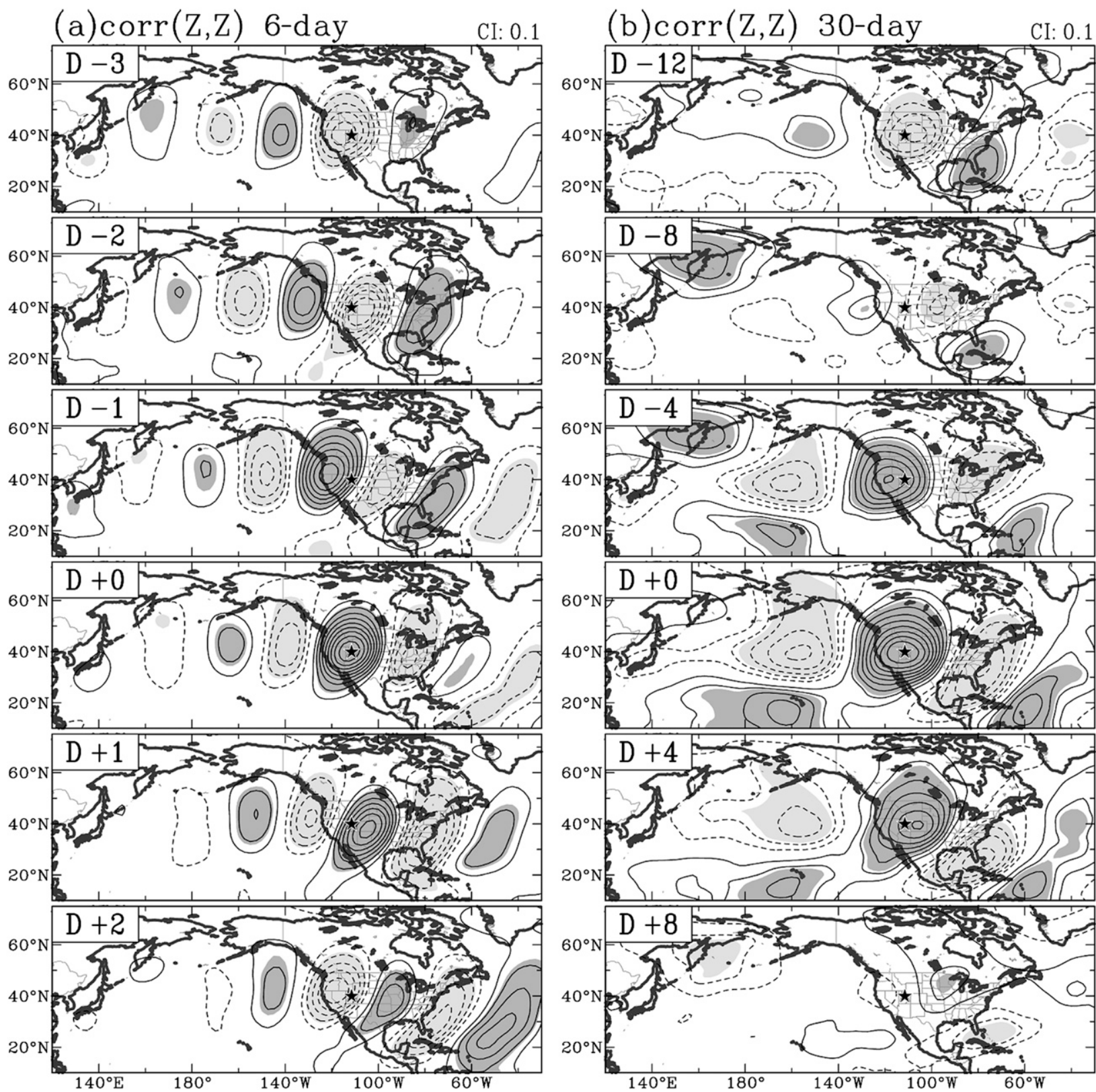

FIG. 9. Correlation maps of bandpassed 300-hPa geopotential height of the NCEP-NCAR reanalyses correlated with that of the KSLC soundings from (a) day -3 to day +2 for the 6 -day mode and (b) from day -12 to day +8 with a 4-day interval for the 30 -day mode. The CI is 0.1 , while the zero contours are omitted. Areas above the $95 \%$ confidence level are shaded. KSLC is marked by a star.

reflects the fact that, during typical winter conditions, the westward-propagating Rossby wave often coexists with the eastward-moving tropical ISV, and the interference between the two likely complicates their propagation signals. Nevertheless, these results suggest that the 6- and the 30-day modes may interact and that their interaction may modulate the characteristics of winter inversions experienced over the Salt Lake Valley, as were substantiated in Figs. 7 and 8.
An examination of the circulation patterns associated with these two modes may provide further insights for forecasting inversion episodes. Figure 10 shows the composite geopotential height at 300 and $850 \mathrm{hPa}$ of the NCEP-NCAR reanalysis (unfiltered) consisting of four combinations of the extreme phases of the 30- and 6-day modes. Under the ridge of the 30-day mode, the superposition of a 6-day mode ridge forms pronounced anticyclonic flows with high pressure anomalies at $850 \mathrm{hPa}$ 
(a) $\mathrm{Z}_{30 \mathrm{~d}}$ ridge \& $\mathrm{Z}_{6 \mathrm{~d}}$ ridge

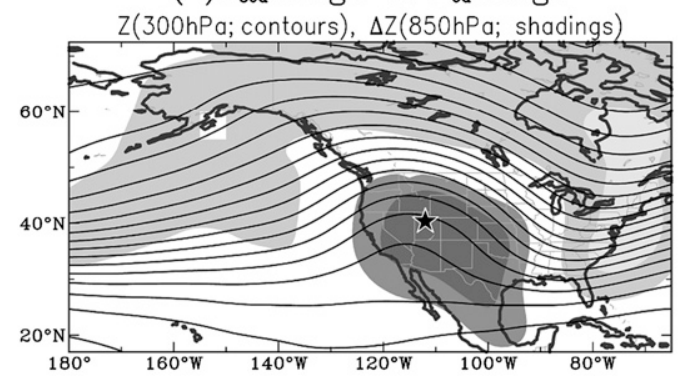

(b) $\mathrm{Z}_{30 \mathrm{~d}}$ ridge \& $\mathrm{Z}_{6 \mathrm{~d}}$ trough

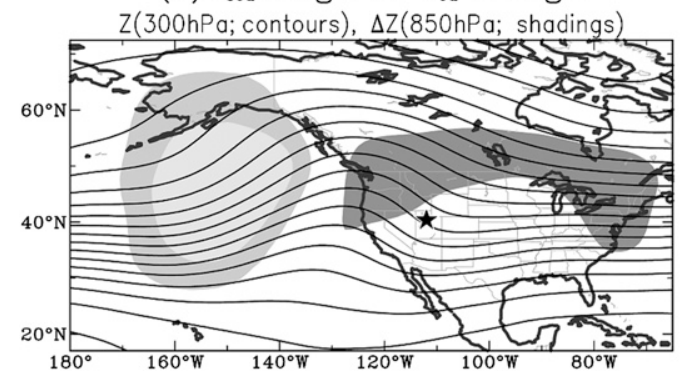

(c) $\mathrm{Z}_{30 \mathrm{~d}}$ trough \& $\mathrm{Z}_{6 \mathrm{~d}}$ ridge

$\mathrm{Z}$ (300hPa; contours), $\Delta \mathrm{Z}(850 \mathrm{hPa}$; shadings)

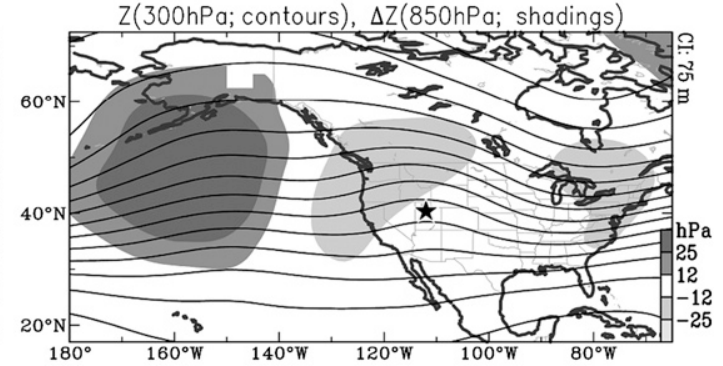

(d) $Z_{30 d}$ trough \& $Z_{6 d}$ trough

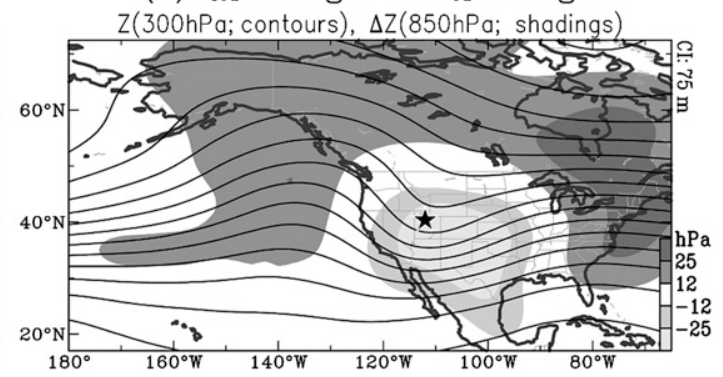

FIG. 10. Composite 300-hPa geopotential height (contours) and the 850-hPa geopotential height anomalies (shadings) for (a) the $Z_{30 \mathrm{~d}}$ ridge (phase 3) with the $Z_{6 \mathrm{~d}}$ ridge (phase 2), (b) the $Z_{30 \mathrm{~d}}$ ridge with the $Z_{6 \mathrm{~d}}$ trough (phase 5), (c) the $Z_{30 \mathrm{~d}}$ trough (phase 7) with the $Z_{6 \mathrm{~d}}$ ridge, and (d) the $Z_{30 \mathrm{~d}}$ trough with the $Z_{6 \mathrm{~d}}$ trough. The CI is $75 \mathrm{~m}$. KSLC is marked by a star.

over the Intermountain West (Fig. 10a). Based on Figs. 7 and 8 , such a synoptic setting warrants persistent surface inversion conditions and valley cold pooling, which will, for the most part, result in particularly high concentrations of PM2.5 near KSLC. When a 6-day mode trough occurs within the 30-day mode ridge, a synoptic trough appears over the Rocky Mountains, but in this case the lower troposphere is characterized by weak high pressure (Fig. 10b). According to Fig. 8c, a capping inversion is likely present at this stage while the surface inversion environment may soon develop.

Under the 30-day-mode trough, a concurring 6-daymode ridge creates weak ridging over KSLC with a weak 850-hPa low pressure zone to the northwest (Fig. 10c). Both types of inversion situations would be expected to dissipate at this stage (cf. Fig. 8g). When the troughs of the 6- and 30-day modes simultaneously occur over KSLC (Fig. 10d), a deep and extensive synoptic trough dominates the Intermountain West. Under such circumstances, inversions are least likely and the PM2.5 concentrations will be at their lowest. These circulation patterns are generally consistent with previous studies (e.g., Reeves and Stensrud 2009). While consistent, the analysis here takes our understanding one step further to show that such circulation patterns and the associated inversion scenarios result from a collective interaction of two atmospheric modes: the ISV (30 day) and the synoptic (6 day) modes.

\section{b. Possible null cases}

There are times, however, when inversions did not occur despite the fact that the $Z_{30 \mathrm{~d}}$ and $Z_{6 \mathrm{~d}}$ indices indicated that they should. One such example in 2001 is presented in Fig. 11. The time-height evolution of the KSLC geopotential height constructed from the combination of $Z_{30 \mathrm{~d}}$ and $Z_{6 \mathrm{~d}}$ is shown in Fig. 11a (shadings), superimposed with the PM2.5 concentration (solid line) and inversion days (dots and circles) in Salt Lake City. While both case A (5 January 2001) and case B (5 February 2001) appear to be under the combined influences of the 30- and 6-day ridges, only case A features a persistent inversion with elevated PM2.5. The synoptic evolutions of these two cases are shown in Figs. 11b and 11c for 3 days in terms of the geopotential height at $300 \mathrm{hPa}$ and the temperature gradients between $775 \mathrm{hPa}$ and $10 \mathrm{~m}$, using the NARR data. An apparent difference in the synoptic pattern is that the ridge system in case A is stronger with its high pressure center closer to KSLC in comparison to case $\mathrm{B}$, which has the ridge near the West Coast, while KSLC is situated at the northeastern edge of the ridge. As shown by the geopotential height anomalies of the combined 30- and 6-day modes (gray boldface contours), the same position difference between the ridges of the two cases is also apparent, with the high pressure center in case $\mathrm{B}$ about $10^{\circ}$ latitude farther 


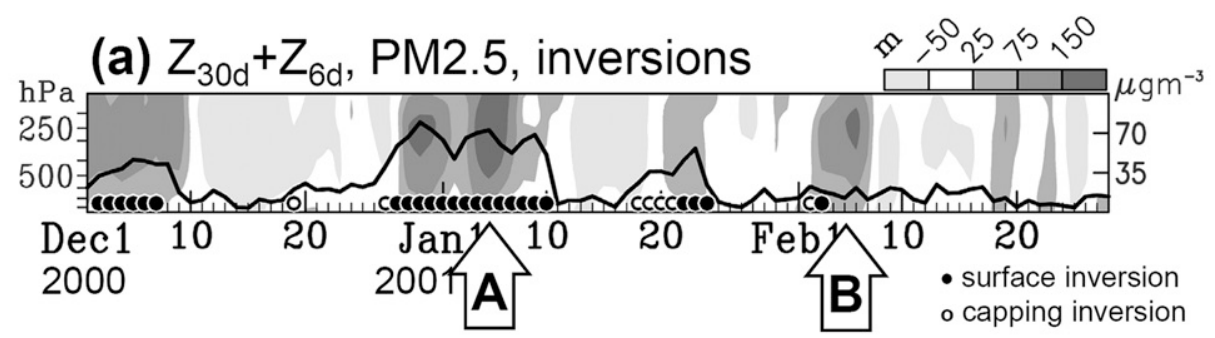

(b) Case A

(c) Case B
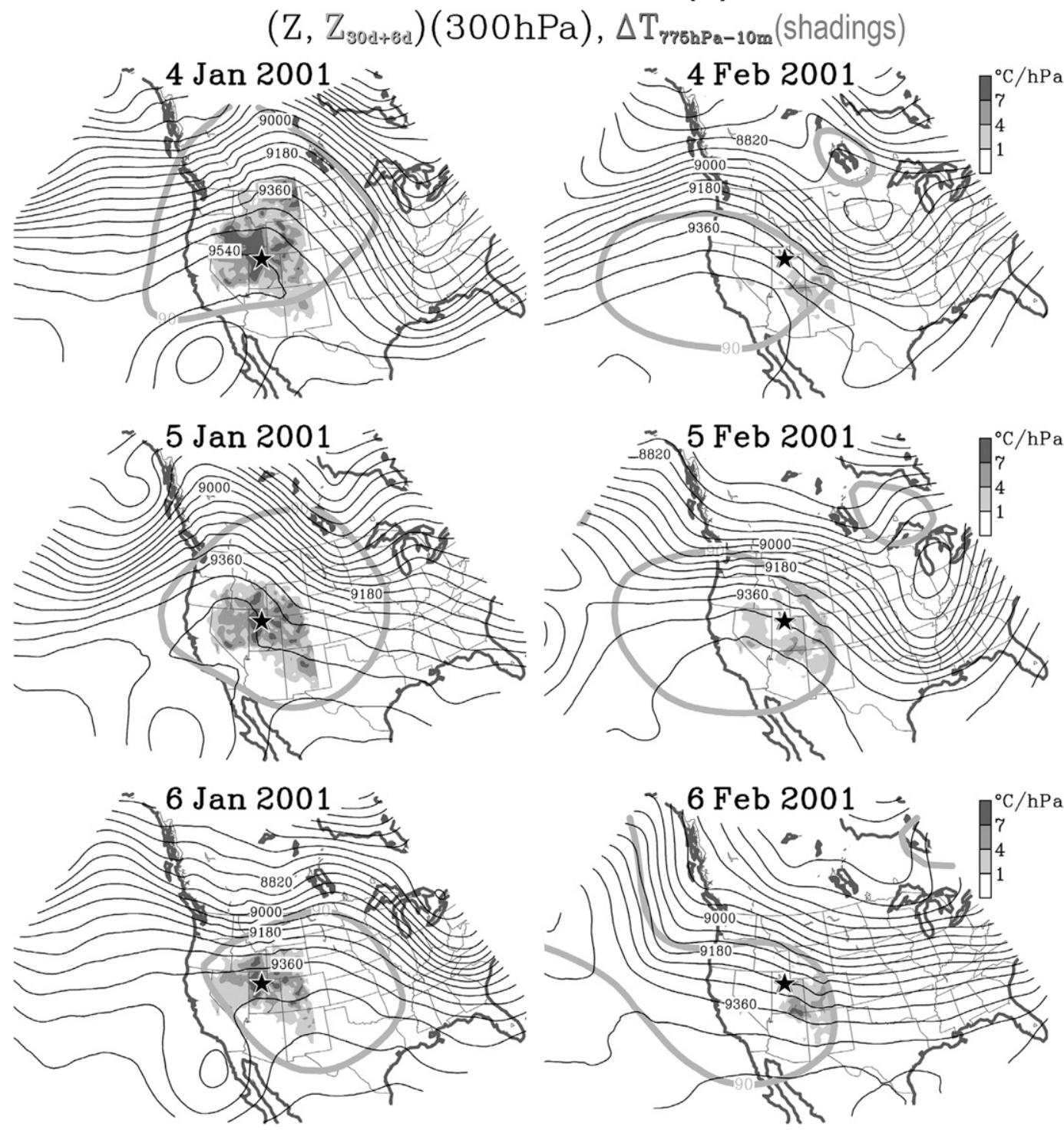

FIG. 11. (a) Time-height evolution of the KSLC geopotential height anomalies constructed by the combination of $Z_{30 \mathrm{~d}}$ and $Z_{6 \mathrm{~d}}$ during the 2000/01 winter, superimposed with time series of the PM2.5 concentration in SLC and inversion cases (dots and circles). The 3-day synoptic evolutions of the 300-hP geopotential height (contours), the combination of $Z_{30 \mathrm{~d}}$ and $Z_{6 \mathrm{~d}}$ (thick gray contours of $90 \mathrm{~m}$ ), and the vertical temperature gradients between $775 \mathrm{hPa}$ and $10 \mathrm{~m}$ (shadings) are shown for (b) case A and (c) case B based on the NARR data. The CI for (b) and (c) is $60 \mathrm{~m}$. KSLC is marked by a star. 
southwest of the high pressure center in case A. Inversions were produced with a similar position shift, as indicated by the temperature gradients. In case A inversions occurred over the Great Basin and the Snake River Valley, and in case B inversions took place farther south over the Colorado River valley. As a result, Salt Lake City did not experience inversions during case $\mathrm{B}$ even though KSLC was within the influence of the ridge system.

These results suggest that the development of persistent inversions depends on the strength and positioning of the synoptic ridge, which echoes Reeves and Stensrud (2009). They noted that weak valley cold pools are usually coupled with weak upper-level forcing and that the seasonal (i.e., meridional) position of the synoptic waves also affects the strength of valley cold pools. We estimated the "null cases" such as that of case B in Fig. 11a to account for about 15\% of the total inversion events in Salt Lake City recorded through the 1979-2008 winters. However, situations like case B may not be regarded completely as a null case because, even though the position of the ridge was shifted, persistent inversions still occurred in the Intermountain West over regions other than the Salt Lake Valley.

\section{Summary and conclusions}

Although the association between inversion developments and large-scale circulations is well known, forecasting the life span and subsequent breakdown of persistent inversions remains a challenge. The analysis undertaken in this study illustrates that the development of inversions in the Salt Lake Valley (and likely throughout the Intermountain West) closely follows two key variation modes in the midlatitude circulation: the 6- (synoptic) and the 30-day (ISV) modes. These two modes are driven by distinct dynamics as is reflected in their different dimension and propagation properties. However, their interaction can and does modify the characteristics of the atmospheric waves moving across the Intermountain West and subsequently modulates the inversion development. Moreover, it was established that the 30-day mode has a particularly strong impact on the persistence of surface inversions that, more often than not, lead to high concentrations of PM2.5. On the other hand, the 6-day mode affects both the surface and capping inversions, but exerts less of an influence on the surface inversion in contrast to the 30-day mode.

The results of this study have implications for the limited forecast ability of the duration and offset of winter inversions and poor air quality in the Salt Lake Valley and the surrounding region. Although medium-range forecasts ( $~ 10$ days) have progressed significantly over recent decades, predicting a half cycle of the ISV (15-20 days) is still beyond the capability of numerical weather prediction models. This may explain why predicting the duration and eventual dissipation of persistent surface inversions remains somewhat elusive. Therefore, the approach of climate diagnostics to identify the presence of the 30-day mode at the onset of an inversion event may be an alternative method to forecasting the event duration. The potential of such a method will be reported in a following study.

Finally, it has been observed that precipitation in states along the West Coast such as California and Washington is modulated by the MJO (Mo and Paegle 2005). The results of this study point out a similar modulation in the Intermountain West. The forecast of the tropical ISV and its connection with the midlatitude weather has, to date, been treated as a climate variability issue rather than a weather issue. A considerable amount of effort has been expended in improving the prediction of the MJO through both empirical and dynamical models (Waliser 2005). It was recently shown that the Climate Forecast System (CFS) model developed by NCEP exhibits satisfactory skill in predicting the MJO (Weaver et al. 2009) and extreme weather events in North America (Jones et al. 2009) at up to 3 weeks. Testing of the CFS's potential in terms of inversion prediction for the Intermountain West is underway.

Acknowledgments. Valuable and constructive comments by three anonymous reviewers were highly appreciated. This study was supported by the USDA-CSREES-funded Drought Management, Utah Project, and the Utah Agricultural Experiment Station, Utah State University, as Journal Paper 8159.

\section{REFERENCES}

Billings, B. J., V. Grubišić, and R. D. Borys, 2006: Maintenance of a mountain valley cold pool: A numerical study. Mon. Wea. Rev., 134, 2266-2278.

Blackmon, M. L., 1976: A climatological spectral study of the $500 \mathrm{mb}$ geopotential height of the Northern Hemisphere. J. Atmos. Sci., 33, 1607-1623.

Branstator, G., 1987: A striking example of the atmosphere's leading traveling pattern. J. Atmos. Sci., 44, 2310-2323.

Chen, T.-C., S.-Y. Wang, M.-C. Yen, and A. J. Clark, 2009: Impact of the intraseasonal variability of the western North Pacific large-scale circulation on tropical cyclone tracks. Wea. Forecasting, 24, 646-666.

Holzworth, G. C., 1962: A study of air pollution potential for the western United States. J. Appl. Meteor., 1, 366-382.

_ 1967: Mixing depths, wind speeds and air pollution potential for selected locations in the United States. J. Appl. Meteor., 6, 1039-1044.

Horel, J. D., and C. R. Mechoso, 1988: Observed and simulated intraseasonal variability of the wintertime planetary circulation. J. Climate, 1, 582-599.

Jones, C., J. Gottschalk, L. Carvalho, and W. Higgins, 2009: Probabilistic forecast skill of extreme weather in weeks 1-4 in the United States during winter. 34th Annual Climate 
Diagnostics and Prediction Workshop, Monterey, CA, CPC, 4.02. [Available online at http://met.nps.edu/climate_CDPW09/ documents/Session_4/4.02_Jones_34th_CDPW_Oct09.pdf.]

Kalnay, E., and Coauthors, 1996: The NCEP/NCAR 40-Year Reanalysis Project. Bull. Amer. Meteor. Soc., 77, 437-471.

Knutson, T. R., and K. M. Weickmann, 1987: 30-60 day atmospheric oscillations: Composite life cycles of convection and circulation anomalies. Mon. Wea. Rev., 115, 1407-1436.

Lau, N. C., and M. J. Nath, 1999: Observed and GCM-simulated westward-propagating, planetary-scale fluctuations with approximately three-week periods. Mon. Wea. Rev., 127, 2324-2345.

Lockhart, W. M., 1943: A winter fog in the interior. Characteristic Weather Phenomena of California, MIT Meteorological Papers, Vol. 1, No. 2, 11-20.

Madden, R. A., and P. R. Julian, 2005: Historical perspective. Intraseasonal Variability in the Atmosphere-Ocean Climate System, K.-M. Lau and D. E. Waliser, Eds., Springer, 1-16.

Mesinger, F., and Coauthors, 2006: North American Regional Reanalysis. Bull. Amer. Meteor. Soc., 87, 343-360.

Mo, K. C., and J. N. Paegle, 2005: Pan-America. Intraseasonal Variability in the Atmosphere-Ocean Climate System, K.-M. Lau and D. E. Waliser, Eds., Springer, 95-121.

Reeves, H. D., and D. J. Stensrud, 2009: Synoptic-scale flow and valley cold pool evolution in the western United States. Wea. Forecasting, 24, 1625-1643.

Renwick, J. A., and J. M. Wallace, 1996: Relationships between North Pacific wintertime blocking, El Niño, and the PNA pattern. Mon. Wea. Rev., 124, 2071-2076.
Stull, R., 2006: The atmospheric boundary layer. Atmospheric Science: An Introductory Survey, 2nd ed., J. M. Wallace and P. V. Hobbs, Eds., Academic Press/Elsevier, 375-417.

Waliser, D., 2005: Predictability and forecasting. Intraseasonal Variability in the Atmosphere-Ocean Climate System, K.-M. Lau and D. E. Waliser, Eds., Springer, 389-423.

Wallace, J. M., G. H. Lim, and M. L. Blackmon, 1988: Relationship between cyclone tracks, anticyclone tracks and baroclinic waveguides. J. Atmos. Sci., 45, 439-462.

Weaver, S., W. Wang, and A. Kumar, 2009: Representation of MJO variability in the NCEP Climate Forecast System. 34th Annual Climate Diagnostics and Prediction Workshop, Monterey, CA, CPC, 4.04

Whiteman, C. D., 2000: Mountain Meteorology: Fundamentals and Applications. Oxford University Press, 355 pp.

— X. Bian, and S. Zhong, 1999: Wintertime evolution of the temperature inversion in the Colorado Plateau basin. J. Appl. Meteor., 38, 1103-1117.

—, S. Zhong, W. J. Shaw, J. M. Hubbe, X. Bian, and J. Mittelstadt, 2001: Cold pools in the Columbia Basin. Wea. Forecasting, 16, 432-447.

Wolyn, P. G., and T. B. McKee, 1989: Deep stable layers in the intermountain western United States. Mon. Wea. Rev., 117, 461-472.

Zhong, S., C. D. Whiteman, X. Bian, W. J. Shaw, and J. M. Hubbe, 2001: Meteorological processes affective the evolution of a wintertime cold air pool in the Columbia Basin. Mon. Wea. Rev., 129, 2600-2613. 